\title{
The impact of laparoscopic diverted sleeve gastrectomy with ileal transposition (DSIT) on short term diabetic medication costs
}

\author{
Alper Celik ${ }^{1 *} \mathbb{D}$, Muharrem Asci', Bahri Onur Celik and Surendra Ugale ${ }^{2}$
}

\begin{abstract}
Background: Type 2 diabetes mellitus (T2DM) has gained pandemic proportions becoming a global threat within the last few decades. In parallel to the increasing prevalence, healthcare costs have become a huge economic burden for the hospital and governments. Bariatric surgery has been proven to induce glycemic control in obese type 2 diabetics. However, the cost effectiveness of metabolic surgery in overweight, obese and morbidly obese individuals has not been documented. We aimed to demonstrate the efficacy and reduced diabetic-medication cost after diverted sleeve gastrectomy with ileal interposition (DSIT) in type 2 diabetic individuals followed more than 1 year.
\end{abstract}

Methods: Records of 116 type 2 diabetic patients operated by DSIT at a dedicated metabolic surgery clinic between October 2011 and April 2013 were retrospectively reviewed. A comparison was made between the annual diabetic medication cost before and after surgery using the paired t test. The alterations in BMl and $\mathrm{HbA1c}$ were recorded and analyzed.

Results: Diverted sleeve gastrectomy with ileal interposition led to a marked reduction in BMI and improved glycemic control after 1 year follow-up. Mean $\mathrm{HbA} 1 \mathrm{c}$ levels decreased from a mean of $8.9 \pm 1.7$ to $6.6 \pm 1.11$ year after surgery $(p<0.001)$. Mean preoperative BMI declined from $32.9 \pm 4.3$ to $24.7 \pm 2.7 \mathrm{~kg} / \mathrm{m}^{2}(p<0.001)$. Cost of diabetic medication decreased from a mean 660.08 USD/year to 65.12 USD 1 year after surgery $(p<0.001)$.

Conclusion: Our results have shown that DSIT operation leads to a significantly better glycemic control and lower diabetic medication costs at 1 year.

Keywords: DSIT, Surgery, Cost saving, Type 2 diabetes

\section{Background}

Metabolic Syndrome and especially type 2 diabetes mellitus (T2DM) became a global problem during recent decades. Its prevalence reached $8.3 \%$ among adults and its estimated prevalence for 2030 will be $10.1 \%$, showing a $22 \%$ increase (Buckley et al. 2012). According to International Diabetes Foundation (IDF) 2013 reports, Turkey has the highest prevalence of diabetes in Europe with $14.8 \%$ of adults (International Diabetes Federation 2013). In parallel to this increasing prevalence, co-morbidities and treatment costs display a notable increase and yield

\footnotetext{
*Correspondence: doktoralper@hotmail.com

${ }^{1}$ Metabolic Surgery Clinic, Halaskargazi Cad. Etfal Sokak Kent Pasaji No: 2/2, Sisli, Istanbul, Turkey

Full list of author information is available at the end of the article
}

a huge economic burden for insurance systems (Brennan et al. 2014). The IDF estimated that diabetes would cost the Turkish health care system $6.5 \mathrm{~b}$ USD per year by 2030 . This estimate has already been reached by 2010 . The 2013 report indicates an annual diabetes related cost of 866 USD per patient (International Diabetes Federation 2013; Brennan et al. 2014; Malhan 2011; Malhan and Vlachopioti 2011).

According to national database registry of Turkey, type 2 diabetic patients constitute $95 \%$ of all diabetics and the annual total cost of type 2 diabetes is 5.14 billion Euros. The majority of this amount is utilized for complications, whereby drug costs constitute only $10.5 \%$ of the total expenses in type 2 diabetic patients (Malhan and Vlachopioti 2011). However, with the progression of

\section{黛 Springer}

(c) 2015 Celik et al. This article is distributed under the terms of the Creative Commons Attribution 4.0 International License (http://creativecommons.org/licenses/by/4.0/), which permits unrestricted use, distribution, and reproduction in any medium, provided you give appropriate credit to the original author(s) and the source, provide a link to the Creative Commons license, and indicate if changes were made. 
the disease, drug usage (esp. insulin) increase and none of the currently available medications provide a solution for the continuing progressive beta cell failure (DePaula et al. 2009). Obesity surgery have shown promising and superior results with respect to metabolic control, weight control and the need for medications, by creating a reduced insulin demand and increased insulin activity (Sjöström et al. 2014; Halperin et al. 2014; Aminian et al. 2014; Rubino et al. 2009; Ghiassi et al. 2012; Chiapaikeo et al. 2014).

Currently, the most widespread procedures in obesity surgery are gastric bypass and sleeve gastrectomy. Unfortunately, the third most widespread procedures in terms of frequency are revision operations. Sadly, the word "revision" represents the disability and inefficiency of the operations performed. Just like any other field in surgery, obesity surgery also has a learning curve of its own and it is obvious that the reason of insufficient weight loss/ weight regain problems occurring within the first year after surgery is technical incompetency. However, longterm follow-up results of the patients who have undergone gastric banding or sleeve gastrectomy prove that the main problem reveals itself 5 years after surgery and one-third of those patients require revision or additional surgical intervention (Chiapaikeo et al. 2014).

Diverted sleeve gastrectomy with ileal transposition (DSIT) consists of a gastric sleeve or fundectomy together with duodenal diversion and interposition of a long segment of ileum between the first centimeters of duodenum and 50th $\mathrm{cm}$ of jejunum. This operation has been shown to be safe and effective especially for obese and overweight patients with T2DM (DePaula et al. 2009).

The aim of the present study was to demonstrate the efficacy and reduced diabetic-medication cost after DSIT in type 2 diabetic individuals.

\section{Methods}

Study design

We retrospectively analyzed the prospectively collected data of 206 type 2 diabetic patients operated at a "Center of Excellence in Bariatric and Metabolic Surgery" at Taksim German Hospital between October 2011 and April 2013. All patients underwent the same surgical procedure (DSIT) carried out by the same surgical team. Of the 206 patients, 116 cases with complete 1-year postoperative follow up were enrolled in the study. Institutional Ethical Committee approval was obtained before the study was set up (14.11.2011-\#11-07).

Inclusion criteria were at least 3 years duration of T2DM under stable medical treatment, HbA1c $>7 \%$ for more than 3 months, weight stability, defined as no significant change ( $>3 \%$ ) within the last 3 months and BMI
$>25 \mathrm{~kg} / \mathrm{m}^{2}$. Patients were excluded if they had a fasting $\mathrm{C}$ peptide level $<0.5 \mathrm{ng} / \mathrm{ml}$ or Anti GAD (Glutamic Adenosine De-carboxylase) Antibody positivity. Other exclusion criteria were previous major abdominal surgery, pregnancy, severe eating disorders and usage of medications for eating disorders.

\section{Surgical procedure}

All patients underwent the laparoscopic DSIT operation, as previously described (Celik et al. 2014). Briefly, we start with a sleeve gastrectomy or fundectomy (depending on the BMI) and progress with duodenal transection $2-3 \mathrm{~cm}$ from the pylorus. This decision was based on patients' BMI. Fundectomy was performed, leaving all antrum intact, in patients with BMI $25-30 \mathrm{~kg} / \mathrm{m}^{2}$. Sleeve gastrectomy with $40 \mathrm{~F}$ calibration plug was performed in patients with BMI $30-35 \mathrm{~kg} / \mathrm{m}^{2}$. Sleeve gastrectomy with $34 \mathrm{~F}$ calibration plug was performed in patients with BMI $>35 \mathrm{~kg} /$ $\mathrm{m}^{2}$. The main rational for individual applications was not to cause weight loss more than expected due to excessive mechanical restriction. The sleeved stomach is transferred to the lower abdomen through a transverse mesocolic opening. The last $30 \mathrm{~cm}$ of ileum is preserved and a $170 \mathrm{~cm}$ segment of distal ileal segment is interposed in between the duodenal end of the stomach and $50 \mathrm{~cm}$ from the Treitz ligament. Ileal ends are anastomosed to each other and all the mesenteric defects are closed one by one using $3 / 0$ polypropylene (Fig. 1 ). All patients received routine multivitamin supplements for at least 6 months after surgery.

\section{Outcome parameters}

All drug names and their doses were obtained from the BOLD (Bariatric Outcomes Longitudinal Database) system and transferred to create Excel files. The change in $\mathrm{BMI}$ and HbAlc were also recorded and analyzed. The drug costs were obtained from national social insurance system database and listed. Drug doses and the total daily usage was documented; costing on a daily and annual basis was evaluated accordingly. The costs have been measured in Turkish Liras (TL) and transferred to United States Dollars (USD) based on currency exchange rate of Turkish Central Bank on April 24, 2015. One $\mathrm{USD}=2.7174 \mathrm{TL}$, http://www.tcmb.gov.tr).

\section{Statistical analysis}

All data was transferred to IBM Statistical Package for Social Sciences (SPSS) Statistics 21.0 program for analysis (SPSS Inc., Chicago, IL, USA). The change in all dependent parameters between preoperative and postoperative 1st year was analyzed using paired $t$ test. Statistical significance was set at $\mathrm{p}<0.05$. 


\section{a}
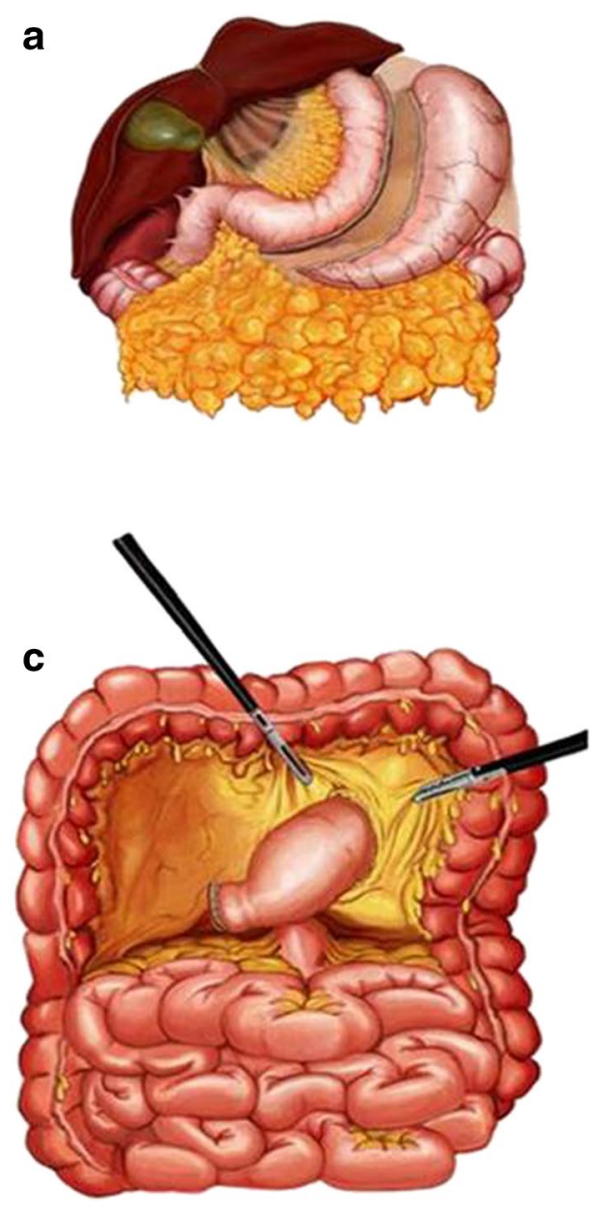

b
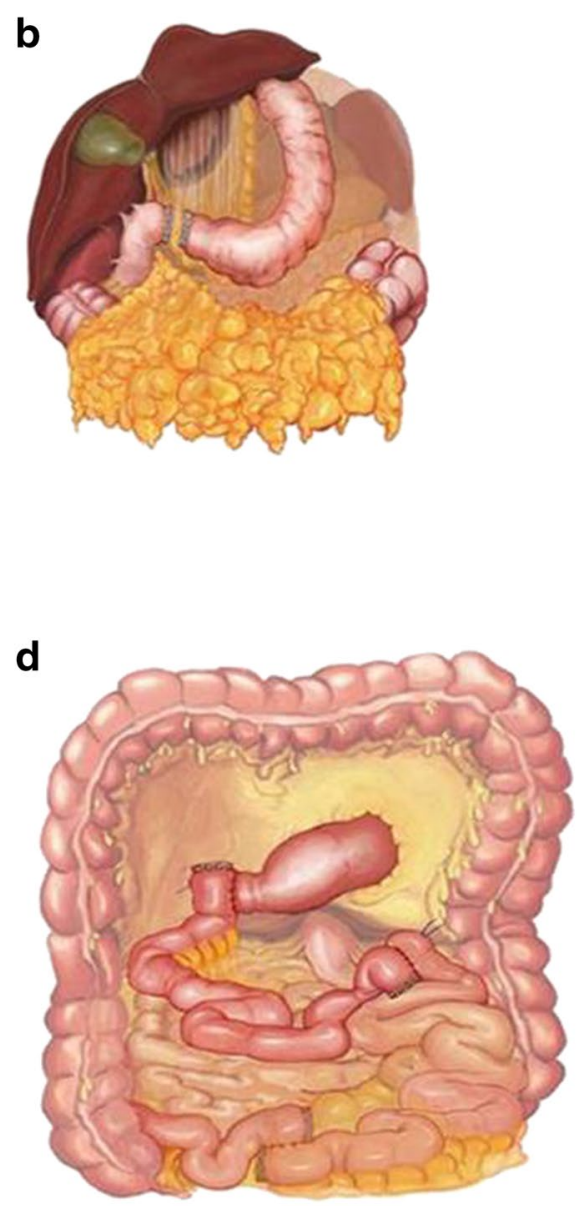

d

Fig. 1 Schematic demonstration of the operation. a Sleeve gastrectomy. b Duodenal transection. c Inframesocolic transfer of the sleeve. $\mathbf{d}$ Interposition of the ileal segment between distal stomach and the proximal jejunum.

\section{Results}

The group of patients consisted of 79 males and 37 females with a mean age of $54.2 \pm 8.7$ (range 24-77) and a mean diabetic duration of $13.3 \pm 5.7$ (range 3-35) years. Mean preoperative BMI was $32.9 \pm 4.7$ (range 25.4-50.2) $\mathrm{kg} / \mathrm{m}^{2}$ and mean postoperative BMI was $24.7 \pm 2.7$ (range 19.1-33.6) $\mathrm{kg} / \mathrm{m}^{2}$. Mean change in BMI was 8.1 (range $0.7-19.2$ ) $\mathrm{kg} / \mathrm{m}^{2}$ and percentage of excess BMI loss (EBMIL) was $72.4 \%$. Mean weight loss at 1 year was $24.3 \pm 8.1$ (range -2.7 to 40.4 ) $\mathrm{kg}$.

Mean preoperative $\mathrm{HbA1c}$ was $8.9 \pm 1.7$ which dropped down to $6.6 \pm 1.11$ year after surgery ( $\mathrm{p}<0.001)$. Of those, 38 patients $(32.8 \%)$ experienced a complete remission (HbA1c $<6 \%$ ), and 30 patients (25.9\%) had a partial remission (HbA1c $=6-6.5 \%$ ).

Postoperatively, 26 patients $(22.4 \%)$ had an HbA1c between 6.5 and $7.5 \%$ ( 2 of them were on oral antidiabetics) and 22 patients (19\%) had a 1 year HbA1c above $7.5 \%$. Among these 22 patients, 20 were on combination oral antidiabetics (OAD), and 2 were using OAD plus single dose of long acting insulin. By the end of 1-year follow up, $58.7 \%$ of patients were under remission $(32.8 \%$ complete remission, and $25.9 \%$ partial remission) without medication. $81.0 \%$ of patients had a mean HbA1c below $7.5 \%$. Twenty-two patients (19\%) had an HbA1c above $7.5 \%$; all of whom were on insulin preoperatively, with a mean HbA1c of $9.9 \pm 1.9$. Mean HbA1c, of this group at 1 year was $8.5 \pm 0.8(\mathrm{p}=0.002)$.

It is of particular interest to note that a total 99 patients (83.2\%) were either on insulin only or combination of OAD with insulin preoperatively, which shows the severity of disease burden in the patient population. Preoperatively, 17 cases were on $\mathrm{OAD}, 16$ were on insulin only and 83 were on insulin plus OAD. In total, 3 of 17 (17.6 \%) on OAD, 3 of the $16(18.75 \%)$ on insulin and 16 of the $83(19.27 \%)$ on insulin + OAD required OAD treatment 1 year after surgery. Postoperatively, $21 \%$ of the patients required antidiabetic treatment 1 year after surgery (Table 1 ).

Preoperatively, the mean cost of anti-diabetic medications was $660.08 \pm 426.05$ USD, which decreased to 
Table 1 Patients pre- and postoperative antidiabetic medication requirement

\begin{tabular}{|c|c|c|c|c|}
\hline \multirow[t]{2}{*}{ Preoperative drugs } & \multicolumn{4}{|c|}{ Postoperative drug use } \\
\hline & $\begin{array}{l}\text { None }(n=92) \\
n(\%)\end{array}$ & $\begin{array}{l}\text { Only OAD }(n=22) \\
n(\%)\end{array}$ & $\begin{array}{l}\text { OAD + insulin }(n=2) \\
n(\%)\end{array}$ & Total $(n=116)$ \\
\hline Only OAD $(n=17), n(\%)$ & $14(82 \%)$ & $3(18 \%)$ & $0(0 \%)$ & $(100 \%)$ \\
\hline Only insulin ( $n=16), n(\%)$ & $13(81 \%)$ & $3(19 \%)$ & $0(0 \%)$ & $(100 \%)$ \\
\hline OAD + insulin $(n=83), n(\%)$ & $65(78 \%)$ & $16(19 \%)$ & $2(2 \%)$ & $(100 \%)$ \\
\hline Total $(n=116), n(\%)$ & $92(79 \%)$ & $22(19 \%)$ & $2(2 \%)$ & $(100 \%)$ \\
\hline
\end{tabular}

$O A D$ oral antidiabetics.

$65.12 \pm 138.23$ USD 1 year postoperatively $(\mathrm{p}<0.001)$ (Table 2).

\section{Discussion}

According to the International Diabetes Federation (IDF) report in 2013, estimated global mortality of diabetes is 5.1 million people which results in an expense of 548 billion USD (International Diabetes Federation 2013). Majority of these expenses are related to co-morbidities treatment rather than drug costs (Malhan and Vlachopioti 2011).

To the best of our knowledge, the present study is the first to analyze the effects of DSIT operation on diabetes related medication costs. Our data clearly demonstrate that surgery revealed more than $90 \%$ reduction in the costs of anti-diabetic medications (660.08 vs. 65.12 USD, $\mathrm{p}<0.001)$. Apart from costs of medication, other disease related costs such as treatment and follow-up of co-morbidities, doctor visits, blood tests and glucose measurements have not been analyzed in the present paper and may be the further investigated in other studies. We think that analysis of other disease related costs may indicate an obvious beneficial effect of surgery in all these parameters.

Within the last few decades, reports of surgical treatment have demonstrated significant benefits on T2DM and other components of metabolic syndrome (Buckley et al. 2012). However, majority of the reports belong to surgery performed on morbidly obese patients. Diverted sleeve gastrectomy with ileal transposition is a novel

Table 2 Mean anti-diabetic medication costs in the preoperative and postoperative 1 year follow-up

\begin{tabular}{|c|c|c|c|}
\hline \multicolumn{2}{|c|}{$\begin{array}{l}\text { Annual drug expenses } \\
\text { (USD) }(n=116) \text {, mean } \pm S D\end{array}$} & \multirow{2}{*}{$\begin{array}{l}\mathbf{T} \\
14.877\end{array}$} & \multirow{2}{*}{$\begin{array}{c}\boldsymbol{p} \text { value } \\
<0.001\end{array}$} \\
\hline Preoperative & $660.08 \pm 426.05$ & & \\
\hline Postoperative 1 year & $65.12 \pm 138.23$ & & \\
\hline Difference in expenses & $594.96 \pm 430.74$ & & \\
\hline
\end{tabular}

USD United States dollars, SD standard deviation. technique that has been shown to be safe and effective even in type 2 diabetic subjects with low BMI (Kumar et al. 2009; Kota et al. 2012). Other reports of DSIT performed on non-morbidly obese type 2 diabetic patients with a mean 39.1 (25-61) months follow up confirmed the beneficial effects and marked remission in diabetes, weight control, hypertension and dyslipidemia (DePaula et al. 2012). These effects have been documented in other publications and its effects on lipid metabolism have been particularly associated with the change in bilioenteric circulation (Yang et al. 2013; DePaula et al. 2010). Similarly, beneficial effects on glycemia have been attributed to the improvement in insulin sensitivity and beta cell function confirmed by prospective studies (Vencio et al. 2011). Other reports of short term (18 months) follow up of non-morbidly obese patients treated by DSIT yielded $80 \%$ remission in T2DM along with appropriate weight control without significant nutritional deficiencies. However, $20 \%$ of patients still required treatment with OAD (Tinoco et al. 2011).

Diverted sleeve gastrectomy with ileal transposition technique is not associated with uncontrollable or severe weight loss. Postoperative weight loss is proportionate with preoperative severity of obesity. According to a study by De Paula et al. normal weight, overweight and obese patients treated by DSIT have lost a mean of $9.4,16.8$ and $23.2 \mathrm{~kg}$, respectively. Irrespective of weight loss, all groups presented marked improvements in insulin output, insulin sensitivity and beta cell function (De Paula et al. 2011a, b).

All the cited articles in this manuscript indicate the efficacy of DSIT operation in controlling all the parameters linked with metabolic syndrome in a wide BMI range. Diverted sleeve gastrectomy with ileal transposition provides high rates of remission for all co-morbidities not only in morbidly obese individuals, but also in normal weight, overweight and obese patients. In the present paper, all patients were either overweight or morbid obese and there were not any patients with normal weight. Mean HbA1c dropped from a mean of $8.9 \pm 1.7$ 
to $6.6 \pm 1.11$ year after surgery. According to Turkish Ministry of Health Diabetes Prevention and Control Program, the targeted level of HbA1c should be below $6.5 \%$ (Ministry of Health of Turkey: Turkey diabetes prevention and control program 2011). In our study, $58.7 \%$ of our patients have achieved an HbA1c below $6.5 \%$ and $81 \%$ of the whole patient group reached an $\mathrm{HbA} 1 \mathrm{c}$ below $7.5 \%$. Only two of these patients were still on OAD, while $79 \%$ of our patients gave up all anti-diabetic medications. Similar to our results, recent publications indicate that surgical modalities offer a more effective mode of treatment for correction of metabolic parameters in T2DM (Cotugno et al. 2015; Schauer et al. 2012).

The main limitation of our study include the retrospective design. Secondly, some details of history and factors that may influence the outcome may not be completely documented. For example, we did not take into account the cost of surgery, hospital stay, clinical follow-up of the surgical group (consultations, exams, hospitalizations), complications, safety of the procedure and the nutritional supplements that these patients should take for life. Thirdly, the present population may not be comparable to the more obese population. Finally, follow-up could only maintained in $56 \%$ of the cases. The low follow-up rate may be due to the low socioeconomic condition, transportation difficulties and tendency of the patients not to return for follow-up once their symptoms are relieved. Due to these restrictions, associations should be interpreted with caution.

In conclusion, DSIT operation can provide lower diabetic medication costs at 1 year. Moreover, an effective weight control in a wide BMI range can be achieved. However, further prospective controlled trials are warranted to confirm these results.

\section{Authors' contributions}

AC: Participated in the design of the study, performed the surgeries, wrote the manuscript. MA: Assisted the surgeries, took role in acquisition of data. BOC: Took role in acquisition and interpretation of data, performed the contact with thestatistician. SU: Revised and drafted the manuscript. All authors read and approved the final manuscript.

\section{Author details}

${ }^{1}$ Metabolic Surgery Clinic, Halaskargazi Cad. Etfal Sokak Kent Pasaji No: 2/2, Sisli, Istanbul, Turkey. ${ }^{2}$ Bariatric and Metabolic Surgery Clinic, Kirloskar Hospital, Hyderabad, India.

\section{Acknowledgements}

The analysis of financial data presented in this article has been carried out by Polar Health Economics and Policy, Hacettepe University Technology Development Zone, Ankara, Turkey.

\section{Compliance with ethical guidelines}

\section{Competing interests}

The authors declare that they have no competing interests.

Funding

The authors declare that they have no funding.

\section{Statement of informed consent}

Informed consent was obtained from all individual participants included in the study.

\section{Statement of human and animal rights}

The study has been approved by the appropriate institutional and/or national research ethics committee and have been performed in accordance with the ethical standards as laid down in the 1964 Declaration of Helsinki and its later amendments or comparable ethical standards.

Received: 17 June 2015 Accepted: 4 August 2015

Published online: 14 August 2015

\section{References}

Aminian A, Daigle CR, Romero-Talamás H, Kashyap SR, Kirwan JP, Brethauer SA et al (2014) Risk prediction of complications of metabolic syndrome before and 6 years after gastric bypass. Surg Obes Relat Dis. 10(4):576-582

Brennan VK, Colosia AD, Copley-Merriman C, Mauskopf J, Hass B, Palencia R (2014) Incremental costs associated with myocardial infarction and stroke in patients with type 2 diabetes mellitus: an overview for economic modeling. J Med Econ 17:469-480

Buckley BS, Harreiter J, Damm P, Corcoy R, Chico A, Simmons D et al (2012) Gestational diabetes mellitus in Europe: prevalence, current screening practice and barriers to screening. A review. Diabet Med 29:844-854

Celik A, Ugale S, Ofluoglu H, Asci M, Celik BO, Vural E et al (2015) Technical feasibility and safety profile of laparoscopic diverted sleeve gastrectomy with ileal transposition (DSIT). Obes Surg 25(7):1184-1190

Chiapaikeo D, Schultheis M, Protyniak B, Pearce P, Borao FJ, Binenbaum SJ (2014) Analysis of reoperations after laparoscopic adjustable gastric banding. JSLS 18(4):e2014.002104. doi:10.4293/JSLS.2014.002104

Cotugno M, Nosso G, Saldalamacchia G, Vitagliano G, Griffo E, Lupoli R et al (2015) Clinical efficacy of bariatric surgery versus liraglutide in patients with type 2 diabetes and severe obesity: a 12-month retrospective evaluation. Acta Diabetol 52:331-336

De Paula AL, Stival AR, Halpern A, DePaula CC, Mari A, Muscelli E et al (2011a) Improvement in insulin sensitivity and $\beta$-cell function following ileal interposition with sleeve gastrectomy in type 2 diabetic patients: potential mechanisms. J Gastrointest Surg 15:1344-1353

De Paula AL, Stival A, Halpern A, Vencio S (2011b) Thirty-day morbidity and mortality of the laparoscopic ileal interposition associated with sleeve gastrectomy for the treatment of type 2 diabetic patients with $\mathrm{BMI}<35$ : an analysis of 454 consecutive patients. World J Surg 35:102-108

DePaula AL, Macedo AL, Mota BR, Schraibman V (2009) Laparoscopic ileal interposition associated to a diverted sleeve gastrectomy is an effective operation for the treatment of type 2 diabetes mellitus patients with BMI 21-29. Surg Endosc 23:1313-1320

DePaula AL, Stival AR, DePaula CC, Halpern A, Vêncio S (2010) Impact on dyslipidemia of the laparoscopic ileal interposition associated to sleeve gastrectomy in type 2 diabetic patients. J Gastrointest Surg 14:1319-1325

DePaula AL, Stival AR, DePaula CC, Halpern A, Vencio S (2012) Surgical treatment of type 2 diabetes in patients with BMI below 35: mid-term outcomes of the laparoscopic ileal interposition associated with a sleeve gastrectomy in 202 consecutive cases. J Gastrointest Surg 16:967-976

Ghiassi S, Morton J, Bellatorre N, Eisenberg D (2012) Short-term medication cost savings for treating hypertension and diabetes after gastric bypass. SOARD 8:269-274

Halperin F, Ding SA, Simonson DC, Panosian J, Goebel-Fabbri A, Wewalka M et al (2014) Roux-en-Y Gastric bypass surgery or lifestyle with intensive medical management in patients with type 2 diabetes: feasibility and 1-year results of a randomized clinical trial. JAMA Surg 149:716-726

International Diabetes Federation (2013) IDF Diabetes Atlas, 6th edn. International Diabetes Federation, Brussels

Kota SK, Ugale S, Gupta N, Modi KD (2012) Laparoscopic ileal interposition with diverted sleeve gastrectomy for treatment of type 2 diabetes. Diabetes Metab Syndr 6:125-131 
Kumar KV, Ugale S, Gupta N, Naik V, Kumar P, Bhaskar P et al (2009) Ileal interposition with sleeve gastrectomy for control of type 2 diabetes. Diabetes Technol Ther 11:785-789

Malhan S (2011) The cost of diabetes complications in Turkey. In: 46th Turkish National Diabetes Congress. 12-16 May 2011, Susesi Deluxe Hotel, Belek, Antalya

Malhan S, Vlachopioti Z (2011) Assessment of the direct medical costs of type 2 diabetes mellitus and its complications in Turkey. In: IDF World Diabetes Congress, abstract: P-1707, 4-8 December 2011, 11, Dubai, United Arab Emirates

Ministry of Health of Turkey (2011) Turkey diabetes prevention and control program 2011-2014. Anıl Matbaası, Ankara. http://www.saglik.gov.tr/HM/ dosya/1-71375/h/turkiye-diyabet-onleme-ve-kontrol-programi.pdf

Rubino F, Moo TA, Rosen DJ, Dakin GF, Pomp A (2009) Diabetes surgery: a new approach to an old disease. Diabetes Care 32:368-371

Schauer PR, Kashyap SR, Wolski K, Brethauer SA, Kirwan JP, Pothier CE et al (2012) Bariatric surgery versus intensive medical therapy in obese patients with diabetes. N Engl J Med 366:1567-1576
Sjöström L, Peltonen M, Jacobson P, Ahlin S, Andersson-Assarsson J, Anveden $\AA$ et al (2014) Association of bariatric surgery with long-term remission of type 2 diabetes and with microvascular and macrovascular complications. JAMA 311:2297-2304

Tinoco A, El-Kadre L, Aquiar L, Tinoco R, Savassi-Rocha P (2011) Short-term and mid-term control of type 2 diabetes mellitus by laparoscopic sleeve gastrectomy with ileal interposition. World J Surg 35:2238-2244

Vencio S, Stival A, Halpern A, Depaula CC, DePaula AL (2011) Early mechanisms of glucose improvement following laparoscopic ileal interposition associated with a sleeve gastrectomy evaluated by the euglycemic hyperinsulinemic clamp in type 2 diabetic patients with BMI below 35. Dig Surg 28:293-298

Yang YH, Yan J, Wu YJ, Lin Y, Yue XL (2013) Impact of sleeve gastrectomy with ileal interposition duodenojejunal bypass operation on lipid metabolism in non-obese type 2 diabetes mellitus patients (Article in Chinese). Zhonghua Wei Chang Wai Ke Za Zhi. 16:273-275

\section{Submit your manuscript to a SpringerOpen ${ }^{\circ}$ journal and benefit from:}

- Convenient online submission

- Rigorous peer review

- Immediate publication on acceptance

- Open access: articles freely available online

- High visibility within the field

- Retaining the copyright to your article

Submit your next manuscript at $>$ springeropen.com 